\title{
MODELING POPULATION DISTRIBUTION IN THE FLOOD-PRONE AREA
}

Beata Calka, Elzbieta Bielecka, Joanna Nowak Da Costa

beata.calka@wat.edu.pl elzbieta.bielecka@wat.edu.pl joanna.nowakdc@wat.edu.pl

\section{INTRODUCTION}

Population density is one of the key parameters for assessing the magnitude of population exposed to flood risk, and the better quality data we have, the better the assessment of risk. The aim of this study is to elaborate a high resolution spatially distributed population density grid, which estimates population at the commune scale with a reliability of over $90 \%$. The novelty of the approach is population density estimation in a regular European grid, based on buildings vector data collected in the national topographic database. Using abductive reasoning in combination with statistics and spatial analysis, the authors extract approximate information about a population from the large scale topographic data. Moreover, linking the obtained population data with the cadastral data - by unique building identifier - allows for regular, quick and census survey independent updates of the population surface. A shortcoming of the approach is the issue of the possible existence of two houses per family, which leads to an overestimation of population. However, in the study area it affected only two of the total fourteen communes by $7-9 \%$.
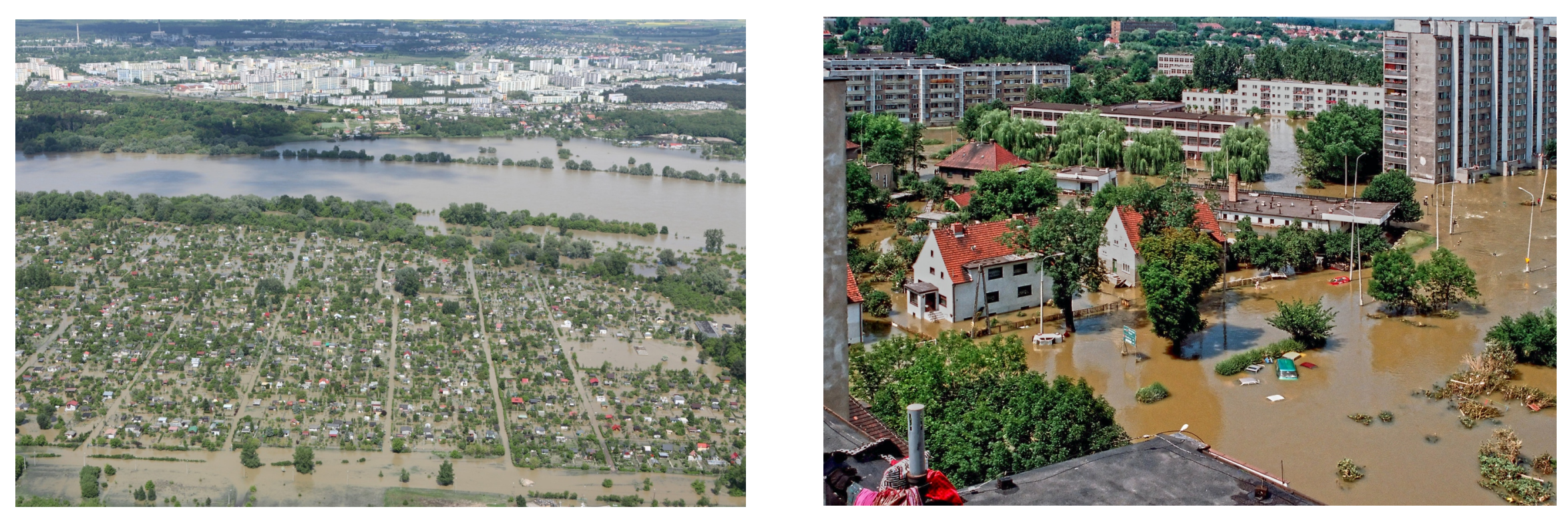

The study area consists of the city of Siedlce and, mostly rural, Siedleckie county located in Mazovia, in the western part of Poland.
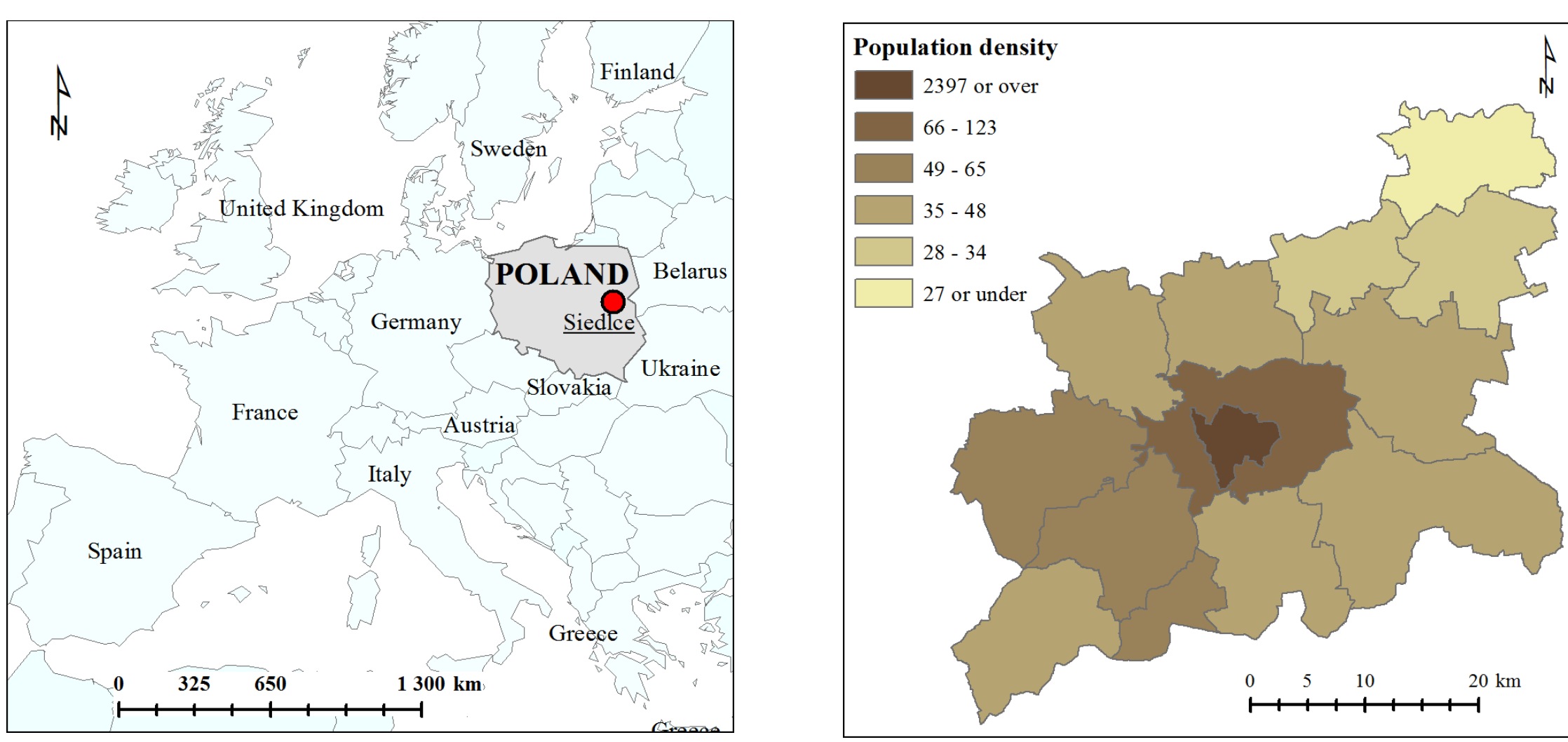

1. NUMBER OF APARTMENT BUILDING DWELLINGS ESTIMATION

The ground truth data of the number of dwellings in each apartment building is unavailable, however it can be estimated on the base of the following equation:

$$
D N_{a b}=2 * S N * F N
$$

Where: $D N_{a b}$ - estimated number of dwellings in an apartment building,

$S N$-number of staircases in an apartment building,

$F N$-number of floors in an apartment building.
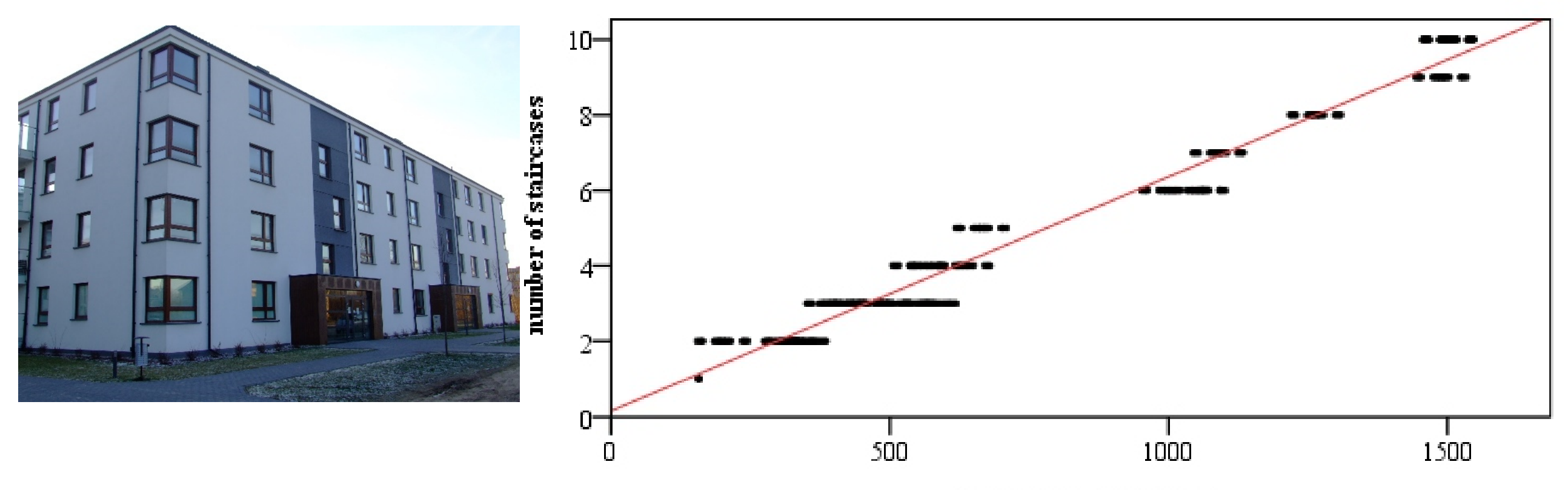

A sample of 310 residential buildings was used to model a statistical relationship between the number of residential building staircases and the apartment building footprint area. This hypothesis was positively

The relationship between the number of an apartment building staircases and the building footprint (area) can be modelled using a simple linear regression:

$$
S N=0.006 * B F+0.021, \text { with } \mathrm{R}^{2}=0.97
$$

Where: $\mathrm{SN}$ - number of staircases in an apartment building,

$$
\mathrm{BF} \text { - building footprint }\left[\mathrm{m}^{2}\right]
$$

\section{COMMUNE POPULATION ESTIMATION}

Assuming the average size of private households $\left(C_{i}\right)$ is known, the building inhabitants number in each of the building types follows the simple rule illustrated in the Table 1 .

\begin{tabular}{|c|c|c|} 
Table 1. Number of inhabitants in a building approximation. \\
\begin{tabular}{|c|c|c|}
\hline Building type & Number of dwellings & $\begin{array}{c}\text { Number of } \\
\text { inhabitants }\end{array}$ \\
\hline single-family house & 1 & $1 * c_{i}$ \\
\hline two-flat residence & 2 & $2 * c_{i}$ \\
\hline apartment building & $D N$ & $D N * c_{i}$ \\
\hline
\end{tabular}
\end{tabular}

3. FINE SCALE POPULATION DENSITY SURFACE CREATION AND ITS ACCURACY VERIFICATION

The estimated number of building dwellings was then multiplied by the tuned average private households for each building located in a particular grid cell, and summed up to arrive at the cell population value. Here, the authors refer to the location of the building as to the building centroid position. The final population density attributed to 1 ha grid varies from 0 to 635 as can be seen from histogram.

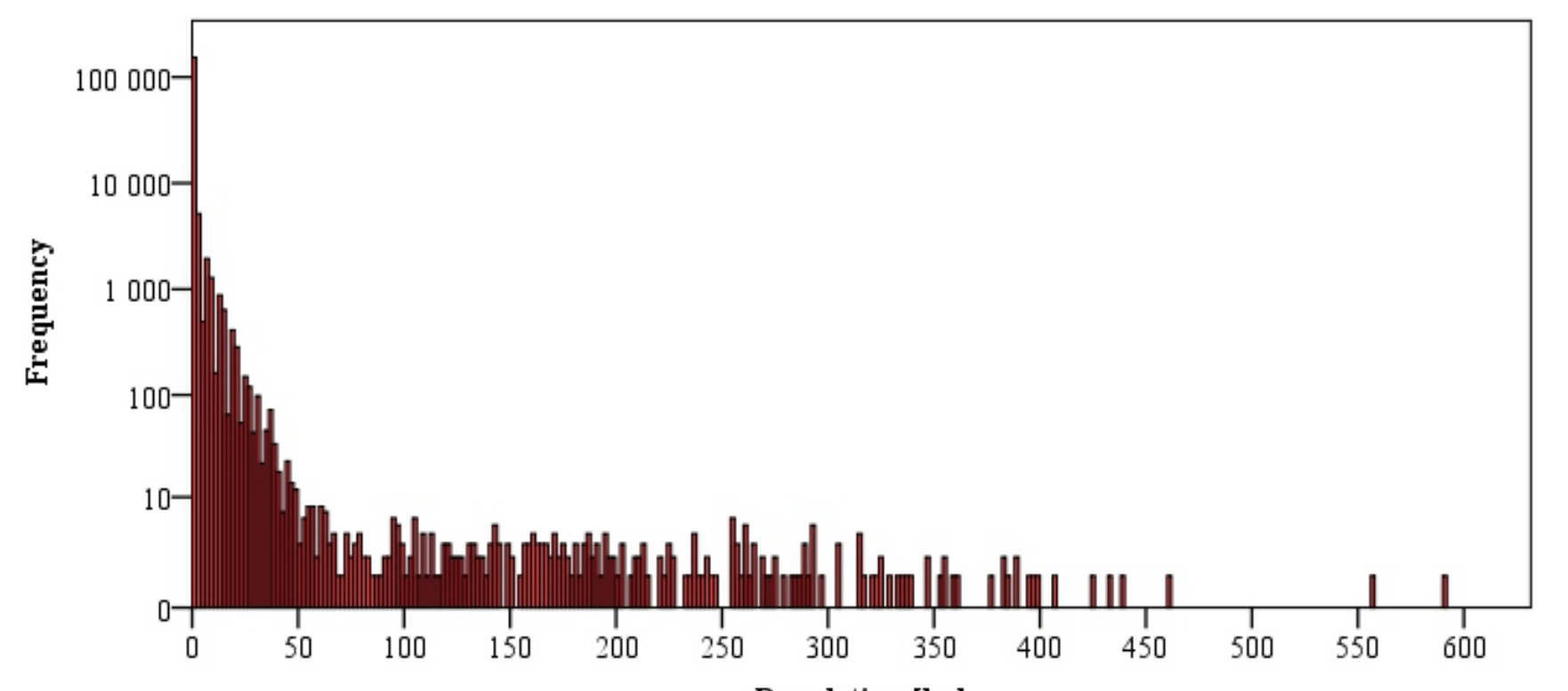

In order to verify the accuracy of the resulting population surface, a comparative analysis was performed The difference in per cents in population counts (MAPE error) varies from -6.3 to +8.85 , when comparing population by commune given by the Central Statistical Office to the total population derived from the interpreted population surface.

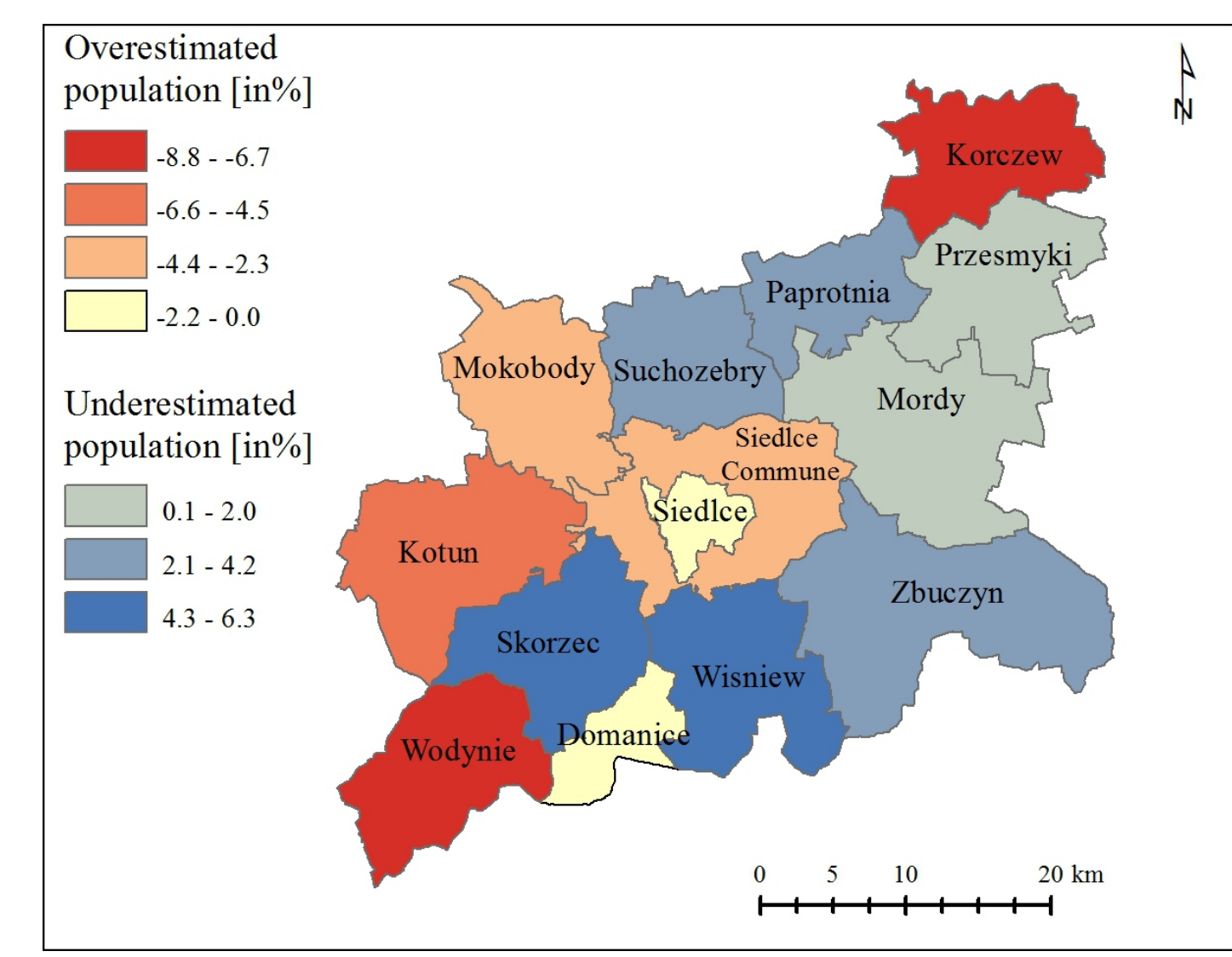

\section{CARTOGRAPHIC VISUALISATION}

The obtained population surface represents detailed high resolution population density data and allows for a quick visual assessment of the population data spatial distribution.

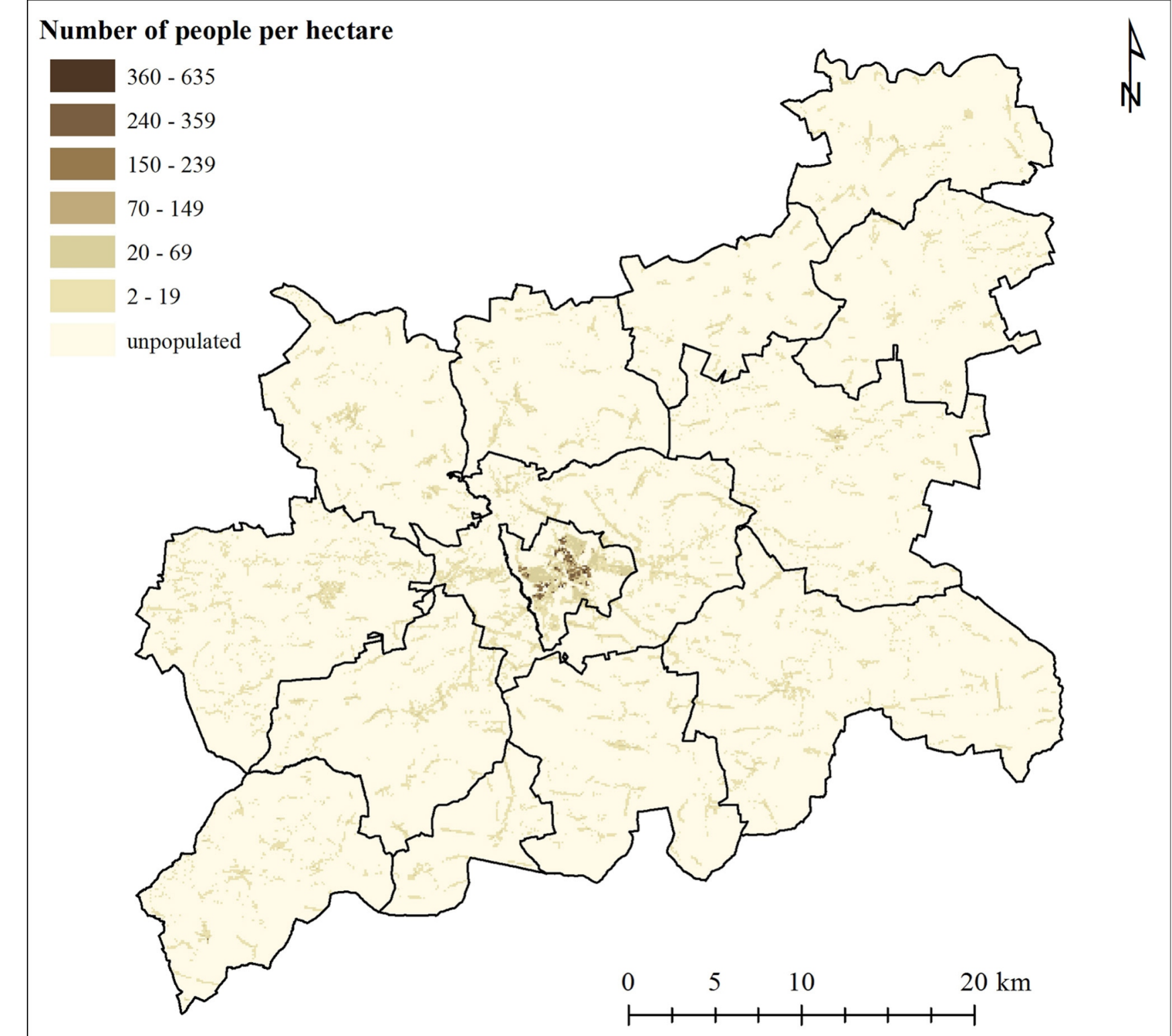

Sharing data on flood risk along with information about the number of people exposed to danger enables a wide and open access for all citizens and it facilitates people prevention and protection measures both in crisis situations and risk mitigation. Usefulness of the data is demonstrated in an example of flood hazard in the study area crossed by two main rivers, the Bug and the Liwiec.
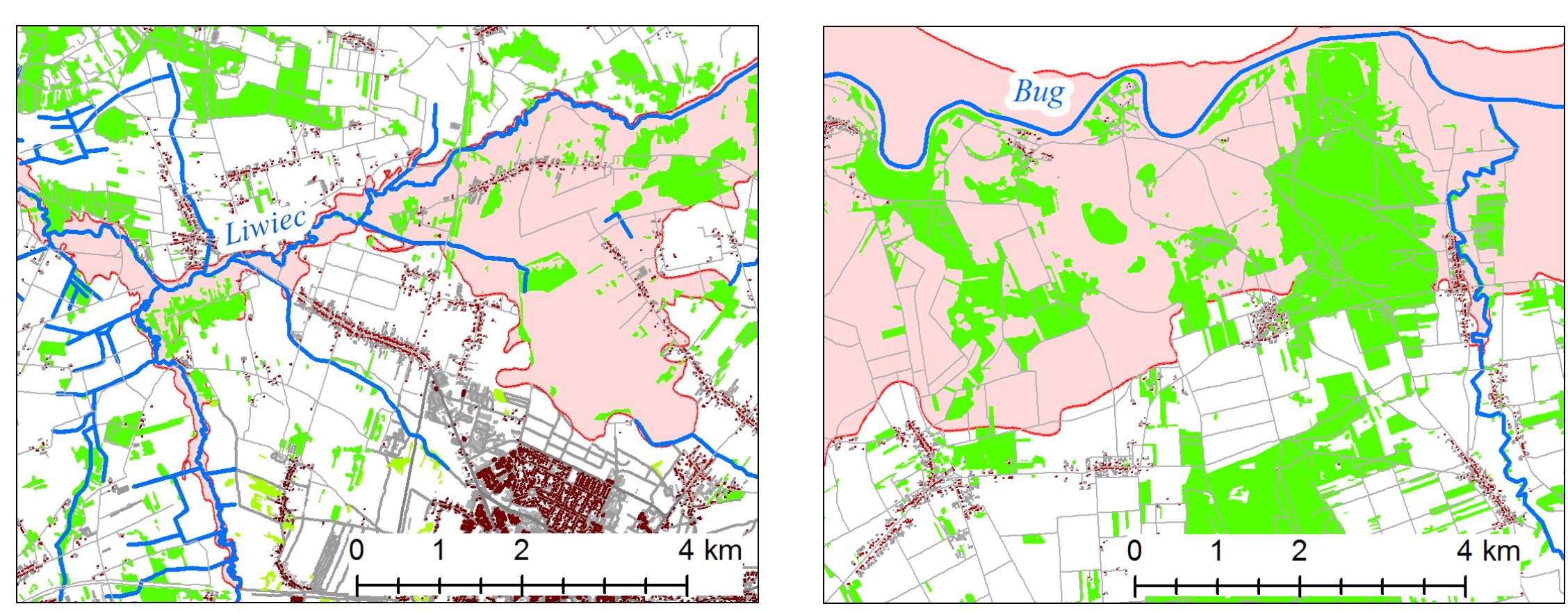